\title{
HUBUNGAN TIPE KEPRIBADIAN OCEAN DAN BRAND TRUST PADA KONSUMEN MASKAPAI PENERBANGAN LOW COST CARRIER
}

\author{
Octavianty, \\ Devi Jatmika ${ }^{1}$ \\ Program Studi Psikologi \\ Universitas Bunda Mulia \\ Jl. Lodan Raya No. 2 \\ Jakarta 14430, Indonesia \\ ${ }^{1}$ e-mail:djatmika@bundamulia.ac.id
}

\begin{abstract}
The need of air transportation is increasing day by day. In order to satisfy this need, airline industries build low cost carrier airlines concept. However, low cost carrier concept may have some risk factors, especially the safety concern of passengers that should be the main priority of the aviation industries. This study aims to determine the relationship between OCEAN personality type and brand trust ofAirAsia's consumers.

Quantitative research method was conducted in this research. The number of sample was 266 users of low cost carrier airline. Sampling technique used was accidental sampling. Data were collected and were statistically analyzed by using Spearman correlation technique. The results in this study indicate that there is a positive and significant correlation between personality type of Extraversion $(r=0.155 ; p<.05)$, conscientiousness $(r=0.216 ; p<.05)$, agreeableness $(r=0.254 ; p<.05)$, openess to experience ( $r=0.613 ; p<.05)$ towards the brand trust. Moreover, there is significantand negative correlation between neuroticsm and brand trust $(r=-0.268$; $p<.05)$.The descriptiveanalysis of brand trust revealed that consumers tend to have low trust to the low cost carrier airline.
\end{abstract}

Keywords: OCEAN personality type; brand trust; low cost carrier

\footnotetext{
Abstrak - Kebutuhan masyarakat akan transportasi udara semakin hari semakin meningkat, sehingga maskapai penerbangan dengan konsep low cost carrier(berbiaya murah) semakin marak.Namun, pada perusahaan maskapai dengan konsep low cost carrier ini, masih terdapat berbagai masalah terutama dalam hal jaminan keamanan dan keselamatan penumpang yang merupakan prioritas utama dalam penerbangan. Penelitian ini bertujuan mengetahui hubungan antara kepribadian tipe OCEAN dan brand trust pada konsumensalah satu maskapai penerbangan low cost carrier.

Metode penelitian yang digunakan ialah metode penelitian kuantitatif. Subjek penelitian sebanyak 266 orang dari berbagai kalangan yang pernah
} 
menggunakan layanan maskapai penerbangan low cost carrier. Teknik sampling yang digunakan adalah accidental sampling. Teknik analisa data menggunakanteknik korelasi Spearman. Hasil dalam penelitian ini menunjukkan bahwa terdapat hubungan yang positif dan signifikan antara tipe kepribadian extraversion $(\mathrm{r}=0.155 ; \mathrm{p}<.05)$, conscientiousness $(\mathrm{r}=0.216 ; \mathrm{p}<.05)$, agreeableness $(\mathrm{r}=0.254 ; \mathrm{p}<.05)$, openess to experience $(\mathrm{r}=0.613 ; \mathrm{p}<.05)$ dengan kepercayaan terhadap merek (brand trust), serta terdapat hubungan negatif dan signifikan antara tipe kepribadian neuroticismdengan kepercayaan terhadap merek (brand trust) $(\mathrm{r}=-0.268 ; \mathrm{p}<.05)$ pada konsumen salah satu maskapai penerbangan low cost carrier. Hasil analisa deskriptif dari kepercayaan konsumen terhadap merek pada maskapai penerbangan low cost carrier cenderung rendah.

Kata kunci: tipe kepribadian OCEAN; kepercayaan terhadap merek; low cost carrier

\section{PENDAHULUAN}

Transportasi udara saat ini mengalami perkembangan yang sangat cepat. Jumlah pengguna jasa industri penerbangan pada tahun 2013 yaitu 68,5 juta orang dan pada tahun 2014 total jumlah penumpang adalah 72,6 juta orang (Kementerian Perhubungan Republik Indonesia, 2015).Transportasi udara menjadi salah satucara alternatif untuk mengangkut penumpang, kargo, dan pos untuk satu perjalanan atau lebih dari satu bandar udara ke bandar udara lain, seperti tercermin dalam Peraturan Menteri Perhubungan nomor 77 tahun 2011.Sebagian maskapai penerbangan memiliki kualitas yang baik dengan harga yang mahal, namun dengan adanya persaingan dalam dunia industri penerbangan tersebut melahirkan maskapai penerbangan dengan sistem Low Cost Carrier(LCC), yaitu biaya operasional yang kecil dengan cara menekan atau mereduksi pengeluaran operasional dan melakukan pelayanan yang serba efisien, sederhana, dan ringkas (Supingah, 2015). Pertumbuhan LCC di Indonesiatumbuh dengan pesat, dapat dilihat dari jumlah pesawat LCC yang mencapai 200 unit hingga akhir tahun 2013 (Ramadhan, 2014). Indonesia National Air Carriers Association (INACA) atau Asosiasi Perusahaan Penerbangan Sipil Indonesia menyatakan kelas Full Service Carrier (FSC) memang hanya memegang porsi yang lebih kecil yakni hanya 20\% pasar penebangan Indonesia, sisanya 80\% dikuasai pasar LCC (Addani \& Nofietasari, 2013).Masyarakat cenderung memilih maskapai penerbangan berbiaya rendah karena daya beli masyarakat relatif terbatas (Hidayat, 2010).

Beberapa merk maskapai dengan konsep LCC di Indonesia seperti Citilink, Lion Air, Sriwijaya Air, Wings Air, Jetstar Asia Airways,AirAsia, Tiger Airways. Dalam operasional LCC dibutuhkan keahlian pengelolaan keuangan yang canggih sebab semua operasi pesawat terbang, termasuk maintenance, pada umunya dilakukan dengan nilai dolar Amerika Serikat, sementara pemasukan dengan rupiah, bisa saja disaat operasi angkut penumpang dijalankan, biaya operasional 
lebih besar daripada pendapatan sehingga maskapai merugi, asumsi ini membawa pada penilaian LCC lebih berpotensi melakukan pengiritan pada maintenance yang berkaitan dengan aspek keselamatan ("Tarif Murah, Aman Terbang", 2015).

Salah satu maskapai penerbangan yang menerapkan sistem LCC adalah maskapai penerbangan AirAsia, yang menjadi fokus dalam penelitian ini.AirAsia merupakan maskapai penerbangan murah asal Malaysia yang berpusat di Kuala Lumpur. Awalnya perusahaan ini milik DRB-HICOM yang berada di bawah pemerintah Malaysia (Lestarini, 2015). Sayangnya manajemen perusahaan ini tidak berjalan dengan baik sehingga merugi hingga USD 40 juta, hingga kemudian diambil alih pada tahun 2001. Di Indonesia perusahaan ini berganti nama menjadi AWAIR (Air Wagon International) namun akhirnya berganti nama menjadi PT Indonesia AirAsia pada tahun 2005.

Reputasi AirAsia sebagai maskapai penerbangan LCC telah mendapatkan penghargaan dari Skytrax selama tujuh tahun ("Prestasi AirAsia", 2015). Maskapai AirAsia sangat meminimalisasi tingkat kecelakaan di dalam berbagaipraktik kerja. Kepatuhannya terhadap peraturan keselamatan menyebabkan AirAsiamenjadi merek yang dapat diandalkan dalam maskapai penerbangan. Namun padabulan Desember 2014, pesawat AirAsia kehilangan kontak dan akhirnya ditemukan terjatuh di Pangkalan Bun, Kalimantan (“Saham AirAsia Anjlok”, 2015). Jatuhnya pesawat AirAsia juga memiliki dampak yang serius pada saham perusahaan penerbangan AirAsia, dimana pada saat jatuhnya pesawat AirAsia, saham turun drastis senilai 8,5\% dari RM 2.94 ke RM 2.69 ("Saham AirAsiaAnjlok", 2015). Dampak lainnya adalah penurunan jumlah penumpang pasca kecelakaan. Presiden Direktur Indonesia maskapai penerbangan AirAsia, Sunu Widyatmoko, menyatakan bahwa maskapai mengalami penurunan penumpang secara drastis, bahkan ia menyebutkan bisnisnya saat ini sedang paceklik walau ia tidak menyatakan persentasenya, namun ada pengaruhnya (Sukmana, 2015).

Pihak Kementerian Perhubungan menyatakan bahwa maskapai yang menjual tiket terlalu murah berpotensi mengabaikan aspek keselamatan penerbangan. Hal ini dikarenakan efisiensi yang dilakukan oleh maskapai membuat maskapai LCC melakukan hal - hal yang diluar kebiasaan maskapai pada umumnya, salah satunya adalah mereduksi biaya, yang kemudian sering disejajarkan dengan kemungkinan pengurangan standar keselamatan ("Tarif Murah Aman Terbang," 2015).Sebagai contoh maskapai Adam Air, dimana pada tanggal 28 Agustus 2007 lalu penerbangan KL 574 jurusan Jakarta - Manado terhempas secara mengerikan ke perairan Majene dan menewaskan 96 penumpang dan 6 awak pesawat. Setelah setahun KNKT mengumumkan bahwa penyebabnya adalah cuaca buruk, kerusakan alat bantu navigasi Inertial Reference System dan 
kegagalan kinerja pilot dalam menghadapi situasi darurat. Efek dari kecelakaan ini adalah pada 18 Juni 2008, maskapai murah yang pernah menjadi terbaik di Indonesia berakhir (Yulianingsih, 2015). Penerbangan nasional dilarang Uni Eropa untuk terbang ke benua tersebut. Kepercayaan publik pada maskapai nasional merosot tajam. Pengaruh dari kecelakaan yang terjadi pada pesawat AirAsia iniadalah menurunnya konsumen yang menggunakan jasa penerbangan AirAsia. Hal ini menunjukkan adanya dampak pada keputusan konsumen untuk menggunakan jasa AirAsia (Sukmana, 2015). Konsep low safety pada LCC ditambah dengan peristiwa kecelakaan yang pernah terjadi dapat mempengaruhi kepercayaan konsumen terhadap merek AirAsia. Menurut Gurviez dan Korchia (dalam Ferrina, 2008) brand trust merupakan variabel psikologis yang mencerminkan sejumlah akumulasi asumsi awal yang melibatkan kredibilitas, integritas, dan citra diri yang baik yang dilekatkan kepada merek tertentu. Brand trustakan menentukan kesetiaan konsumen terhadap merek dan kepercayaan akan berpotensi menciptakan hubungan - hubungan yang bernilai tinggi (Morgan \& Hunt dalam Rizan, Saidani, \& Sari, 2012).

Faktor lain yang dapat dipertimbangkan oleh seseorang dalam menggunakan atau membeli jasa atau produk adalah kepribadian. Stanto dan Lamarto (dalam Iskandar \& Zulkarnain, 2013) menyatakanbahwa saat individu menyadari kebutuhannya, maka pilihan produk harus diidentifikasi untuk memenuhi kebutuhannya. Setiap konsumen memiliki sifat yang berbeda-beda dalam pemilihan produk, yang dipengaruhi oleh kondisi internal dan ekternal. Kondisi eksternal yang dimaksudkan adalah lingkungan dan konformitas dengan teman, sedangkan kondisi internal meliputi keinginan diri sendiri atau ketertarikan tersendiri dari individu ke produk atau jasa tersebut.

Lee (dalam Wardana, 2011) menyatakan dengan mengetahui kepribadian konsumen maka sebuah perusahaan dapat mengidentifikasi ciri konsumen yang dapat menimbulkan kekacauan, konsumen potensial, dan cara menanganinya, sehingga akan berpengaruh pada loyalitas konsumen. Menurut Larsen dan Buss (dalam Mastuti, 2005) kepribadian merupakan sekumpulan trait psikologis dan mekanisme didalam individu yang diorganisasikan, relatif bertahan,dan mempengaruhi interaksi dan adaptasi individu dalam lingkungannya. Trait berlangsung untuk jangka waktu yang lama; kemampuannya untuk memprediksi pola tingkah laku untuk jarak waktu yang panjang merupakan hal yang luar biasa. Costa dan McCrae(dalam Pervin, Cervone, \& John, 2005)mengemukakan teori kepribadian Big Five, yang mengatakan bahwa faktor-faktor didalam Big Fiveterdiri dari neuroticism, extraversion, opennes to experience, aggreableness, dan conscientiousness. 
Individu dengan skor yang tinggi pada skala extraversion ini akan lebih menyayangi, periang, banyak bicara, senang bergabung dengan orang lain, dan menyenangkan. Sebaliknya jika individu dengan skor rendah kemungkinan akan menyendiri, pasif, dan kurang mampu untuk mengekspresikan emosinya (Feist\& Feist, 2009).

Skala Agreeableness membedakan individu yang berhati lembut dengan yang tidak. Individu dengan skor yang tinggi pada trait ini lebih percaya, murah hati, dan baik hati, namun jika individu dengan skor yang rendah pada skala agreeableness umumnya sering mencurigai, pelit, tidak ingin berteman, mudah tersinggung, dan kritis terhadap orang lain (Feist\& Feist, 2009).

Individu dengan tipe kepribadian conscientiousness digambarkan sebagai pribadi yang teratur, penuh pengendalian diri, terorganisasi, ambisius, fokus pada pencapaian, dan disiplin diri. Pada umumnya juga merupakan orang yang pekerja keras, peka terhadap suara hati, tepat waktu, dan tekun. Sebaliknya, pribadi yang rendah skor cenderung tidak terorganisasi, malas, ceroboh, dan tidak berarah-tujuan, dan mudah menyerah jika suatu proyek menjadi sulit (Feist\& Feist, 2009).

Selanjutnya, pribadi yang skor neuroticism berada pada kategori tinggi cenderung mudah menjadi cemas, temperamental, mengasihani diri, emosional, dan rapuh terhadap gangguan yang berkaitan dengan stres. Pribadi yang skorneuroticism-nya rendah biasanya tenang, bertemperamen lembut, dan puas diri (Feist \&Feist, 2009).

Terakhir, seseorang dengan skala openness to experience yang tinggi memiliki keterbukaan cara berpikir dan mau menerima konsep-konsep baru. Pribadi yang secara konsisten mencari pengalaman-pengalaman yang berbeda dan beragam akan memperoleh skor tinggi dalam openness to experience (Feist\& Feist, 2009).

Sebuah studi yang dilakukan oleh Utomo (2013) mengenai kepercayaan pada pedagang internet dan kepribadian Big Five dengan intensi membeli pakaian melalui internet mendapatkan hasil bahwa kepercayaan pada pedagang internet dan kepribadian Big five mampu memprediksi intensi konsumen untuk membeli pakaian melalui internet sebesar 32,4\% $\left(\mathrm{R}^{2}=0.324 ; p=0.01\right)$. Penelitian yang hampir serupa dilakukan oleh Azam, Qiang, dan Sharif (2013),mendapatkan hasil bahwa individu dengan traitextraversion, agreableness, dan openess to experience memiliki kepercayaan pada e-commerce, sedangkan individu dengan trait neuroticism dan conscientiousness tidak memiliki kepercayaan terhadap e-commerce.Perbedaan dengan penelitian sebelumnya adalah penelitian ini menghubungkan trait kepribadian OCEAN dan kepercayaan pada merek (brand trust) AirAsia. 


\section{METODE}

\section{Partisipan}

Partisipan adalah para konsumen jasa penerbangan AirAsia. Subjek penelitian diperoleh sebanyak 223 orang. Peneliti menyebarkan data tersebut pada penumpang di Bandara Soekarno Hatta. Teknik sampling yang telah digunakan oleh peneliti dalam penelitian ini adalah aksidental, yaitu teknik penentuan sampel berdasarkan faktor spontanitas, yang artinya siapa saja yang secara tidak sengaja bertemu dengan peneliti dan sesuai dengan karakteristik, maka orang tersebut dapat digunakan sebagai sampel (Sugiyono, 2014). Karakteristik yang harus dipenuhi dalam penentuan sampel adalah: 1) pernah menggunakan maskapai penerbangan AirAsia; 2) berusia lebih dari 30 tahun. Pemilihan subjek di atas usia 30 tahun karena menurut McCrae dan Costa (Feist, 2006) setelah seseorang berusia lebih dari 30 tahun trait yang ada akan stabil dibanding kan seseorang yang berusia dibawah 30 tahun. Pada penelitian ini karakteristik subjek diberlakukan untuk kedua variabel.

\section{Desain}

Penelitian ini menggunakan metode kuantitatif, dan jenis penelitian yang digunakan adalah penelitian korelasional sesuai dengan tujuan utama dari penelitian ini untuk mengetahui hubungan antara variabel satu dengan variabel lainnya (Gravetter \& Forzano, 2012).

\section{Instrumen}

Instrumen yang digunakan dalam penelitian adalah kuesioner. Instrumen untuk mengukur lima trait kepribadian OCEAN menggunakan instrumen Big Five Inventory yang telah diadaptasi dalam bahasa Indonesia oleh Ramdhani (2012). Instrumen Big Five Inventory dalam penelitian ini diuji kembali kepada 61 subjek yang berusia 30 tahun ke atas, dengan hasil sebagai berikut: extraversion (8 item : $a=.739$ ), aggreableness (8 item : $a=.744$ ), conscientiousness (9 aitem : $a=.730$ ), neuroticism ( 8 aitem : $a=.818$ ), openness (6 aitem : $a=.716$ ) dengan rentang validitas .289 -.658 .

Variabel brand trust yang diukur terdiri dari dua dimensi yaitu viability dan intentionality berdasarkan model pengukuran Delgado dan Ballester(2003). Skala brand trust telah diujikan 
kepada 61 orang dewasa yang menghasilkan koefisien reliabilitas alpha sebesar .887 dengan rentang validitas sebesar $.398-.655$.

\section{Prosedur}

Pada tahap awal, peneliti mencari informasi untuk membuat latar belakang. Kemudian setelah itu, penelitimenggali landasan teori dari kedua variabel. Selanjutnya, peneliti mencari alat ukur untuk kepribadian OCEAN dan brand trust. Alat ukur yang diperoleh melewati uji keterbacaan, kemudiandilakukan uji coba kepada 61 orang responden. Setelah itu peneliti menghitung nilai reliabilitas dan validitasnya didapat item yang gugur, item yang gugur akan dibuang sehingga semua item akan valid dan reliabel. Setelah itu peneliti menyebarkan alat ukur tersebut kepada 300, sebanyak 34 kuesioner tidak dikembalikan oleh responden dan 43 kuesioner tidak dapat digunakan datanya karena tidak lengkap dalam pengisian atau mengisi di satu pilihan jawaban saja, sehingga data yang dapat diolah sebanyak 223 orang responden.

\section{Teknik Analisis}

Penelitian ini menggunakan teknik analisis korelasi Spearman untuk melihat hubungan antara lima tipe kepribadian OCEAN dengan kepercayaan merek pada maskapai penerbangan AirAsia.

\section{ANALISIS DAN HASIL}

\section{Karakteristik Partisipan}

Deskripsi karakteristik partisipan penelitian ditunjukkan dalam Tabel 1 di bawah. Dari data di atas, dapat diketahui bahwa gambaran subjek berdasarkan jenis kelamin adalah sebagai berikut, untuk laki - laki sebanyak 102 orang subjek dengan persentase sebesar 45,7\% dan untuk perempuan sebanyak 121 orang subjek dengan persentase sebesar 54,3\%. Hasil menunjukkan bahwa profil responden mayoritas berjenis kelamin perempuan. Berdasarkan usia mulai dari usia $30-\geq 50$ tahun. Responden didominasi oleh usia 30 - 35 tahun dengan persentase sebesar 41,7\% karena pada usia tersebut yang lebih bersedia untuk berpartisipasi dalam penelitian ini. Latar belakang pendidikan yang beragam, mulai dari SMP hingga S2. Responden didominasi dengan latar belakang pendidikan S I dengan persentase 59,6\%. Berdasarkan pekerjaan, responden dalam penelitian ini memiliki berbagai pekerjaan, mulai dari karyawan swasta sampai ibu rumah tangga, responden didominasi 
oleh pekerjaan sebagai karyawan swasta dengan persentase sebesar 58,7\%. Kemudian pada intesitas diketahui bahwa intensitas tertinggi dalam menggunakan maskapai AirAsiadalam satu tahun adalah 1 - 3 kali dengan persentase sebesar $64,1 \%$.

Tabel 1.

Karakteristik Partisipan

\begin{tabular}{cccc}
\hline Deskripsi & Kategori & Frekuensi & Persentase \\
\hline Jenis Kelamin & Laki - laki & 102 & $45,7 \%$ \\
& Perempuan & 121 & $54,3 \%$ \\
Usia & $30-35$ tahun & 93 & $41,7 \%$ \\
& $36-40$ tahun & 54 & $24,2 \%$ \\
& $41-45$ tahun & 34 & $15,2 \%$ \\
$46-50$ tahun & 24 & $10,8 \%$ \\
& $\geq 50$ tahun & 18 & $8,1 \%$ \\
Pendidikan & & & \\
& SMP & 8 & $3,6 \%$ \\
& SMA & 42 & $18,8 \%$ \\
& D I & 1 & $4 \%$ \\
D III & 19 & $8,5 \%$ \\
Srekuensi & S I & 133 & $59,6 \%$ \\
menggunakan & $1-3$ kali & 20 & $9 \%$ \\
& $4-6$ kali & 143 & $64,1 \%$ \\
& $7-9$ kali & 51 & $22,9 \%$ \\
& & 29 & $13 \%$ \\
\hline
\end{tabular}

\section{Uji Psikometri Instrumen Penelitian}

Hasil uji reliabilitas terhadap 16 item pada skala brand trust diperoleh koefisien alpha sebesar 0,873 dengan rentang validitas 0,270 - 0,664. Hasil tersebut menunjukkan bahwa skala brand trust adalah reliabel dan valid.

Tabel 2.

Hasil Analisis Validasi InstrumenKepribadian

\begin{tabular}{|c|c|c|c|c|}
\hline Dimensi & Reliabilitas & Keterangan & Rentang validitas & keterangan \\
\hline Extraversion & 0.821 & Reliabel & $0.352-0.656$ & Valid \\
\hline Agreeableness & 0.759 & Reliabel & $0.413-0.511$ & Valid \\
\hline Conscientiousness & 0.827 & Reliabel & $0.446-0.604$ & Valid \\
\hline Neuroticism & 0.792 & Reliabel & $0.427-0.656$ & Valid \\
\hline $\begin{array}{l}\text { Openness } \\
\text { experience }\end{array}$ & 0.873 & Reliabel & $0.270-0.664$ & Valid \\
\hline
\end{tabular}


Dari tabel 2 di atas, juga diketahui bahwa kelima tipe kepribadian memiliki nilai reliabilitas di atas 0.6 sehingga sudah dapat dianggap reliabel sebagai alat ukur, dan pada rentang validitas yang berkisar 0.3 - 0.6 sehingga sudah dapat dikatakan valid.

\section{Uji Normalitas Data}

Dari hasil uji normalitas yang telah dilakukan, data yang diperoleh menunjukkan data tidak normal, dengan nilai signifikansi untuk kepribadian sebesar $0.012(p<0.05)$. dan nilai signifikansi untuk variabel brand trust sebesar $0.020(p<0.05)$.

\section{Uji Hipotesis}

Tabel 3.

Hubungan Antara Lima Tipe Kepribadian Dengan Brand Trust

\begin{tabular}{llllllll}
\hline & & \multicolumn{1}{c}{ Extra } & \multicolumn{1}{c}{ Cons } & \multicolumn{1}{c}{ Agree } & \multicolumn{1}{c}{ Neuro } & \multicolumn{1}{c}{ Open } & BT \\
\hline Brand trust & Spearman's rho & $0.155^{* *}$ & $0.216^{* *}$ & $0.254^{* *}$ & $-0.268^{* *}$ & $0.163^{* *}$ & 1 \\
& Sig. (2-tailed) & 0.021 & 0.001 & 0.000 & 0.000 & 0.015 & \\
& N & 223 & 223 & 223 & 223 & 223 & 223 \\
\hline
\end{tabular}

Dari tabel 3 di atas, dapat diketahui nilai korelasi Spearman antara tipe extraversion dengan brand trust adalah $0.155(p<0.05)$.Hal ini berarti terdapat hubungan korelasi positif antara variabel tipe kepribadian extraversion dengan brand trust.Nilai korelasi Spearman antara tipe conscientiousness dengan brand trust adalah $0.216(p<0.05)$. Hal ini berarti terdapat hubungan korelasi positif antara variabel tipe kepribadian conscientiousness dengan brand trust.Nilai korelasi Spearman antara tipe agreeableness dengan brand trust adalah $0.254(p<0.01)$. Hal ini berarti terdapat hubungan korelasi positif antara variabel tipe kepribadian agreeableness dengan brand trust. Dapat diketahui nilai korelasi Spearman antara tipe neuroticism dengan brand trust adalah $0,268(p<0.01)$. Hal ini berarti terdapat hubungan korelasi negatif antara variabel tipe kepribadian neuroticism dengan brand trust.Terakhir, pada tipe kepribadian openness to experience, diketahui nilai korelasi Spearman antara tipe openess dengan brand trust adalah $0.163(p<0.05)$, yang berarti terdapat hubungan korelasi positif antara variabel tipe kepribadian openness dengan brand trust.

\section{Gambaran Brand Trust terhadap maskapai AirAsia}

Dalam penelitian ini, data brand trust konsumen maskapai AirAsiadiolah dan dibagi menjadi dua kategori dengan menggunakan persentil yaitu, cenderung tinggi dan cenderung rendah. 
Tabel 4.

Kategori brand trust

\begin{tabular}{ccc}
\hline \hline Total skor & \multicolumn{2}{c}{ Kategori brand trust } \\
Frekuensi & Klasifikasi \\
\hline$\leq 43$ & 58 & Sangat rendah \\
$47-44$ & 68 & Rendah \\
$49-48$ & 49 & Tinggi \\
$64-50$ & 48 & Sangat Tinggi \\
\hline \hline
\end{tabular}

Dari tabel di atas, dapat diketahui bahwa sebanyak 58 orang memiliki brand trustpada maskapai AirAsiadengan kategori cenderung sangat rendah, 68 orang memiliki brand trust rendah dan sebanyak 49 orang memiliki brand trust yang cenderung tinggi dan 48 orang cenderung sangat tinggi. Jadi dapat disimpulkan, brand trust konsumen masih cenderung rendah.

Tabel 5.

Respon Pertanyaan open - ended

\begin{tabular}{|c|c|c|c|}
\hline Pertanyaan & Jawaban & Frekuensi & Persentase \\
\hline & - Harga murah dan banyak promo & 140 & 62.8 \\
\hline Alasan menggunakan & - Penerbangan yang aman dan nyaman & 40 & 17.9 \\
\hline AirAsia & - Banyak pilihan jam dan rutenya & 15 & 6.73 \\
\hline & - Terjamin dengan keselamatannya & 148 & 66.4 \\
\hline $\begin{array}{l}\text { Tanggapan anda mengenai } \\
\text { keselamatan maskapai }\end{array}$ & $\begin{array}{l}\text { - Sudah sesuai dengan standart } \\
\text { penerbangan }\end{array}$ & 34 & 15.2 \\
\hline AirAsia" & - Belum terjamin karena beberapa hal & 19 & 8.52 \\
\hline & $\begin{array}{l}\text { - Semakin ditingkatkan dan sudah ada } \\
\text { perbaikan dari maskapai AirAsia }\end{array}$ & 55 & 24.66 \\
\hline Pendapat & - Takdir di tangan Tuhan & 50 & 22.42 \\
\hline $\begin{array}{lr}\text { keselamatan } & \text { maskapai } \\
\text { AirAsiapada } & \text { waktu } \\
\text { kecelakaan tahun } & 2014 ?\end{array}$ & $\begin{array}{l}\text { - Tetap percaya, karena peluang } \\
\text { kecelakaan dari } 5 \text { tahun terakhir } \\
\text { hanya } 1: 10\end{array}$ & 31 & 13.9 \\
\hline \multirow[b]{3}{*}{$\begin{array}{l}\text { Permasalahan yang pernah } \\
\text { anda temui }\end{array}$} & - Delay yang cukup lama & 67 & 30 \\
\hline & - Tidak ada & 57 & 25.6 \\
\hline & $\begin{array}{l}\text { - Tidak ada permasalahan yang } \\
\text { berarti jika masalah tersebut dapat } \\
\text { diselesaikan tidak perlu diungkit } \\
\text { kembali }\end{array}$ & 48 & 21.5 \\
\hline \multirow{3}{*}{$\begin{array}{l}\text { Mengapa masih } \\
\text { menggunakan AirAsia? }\end{array}$} & AirAsiaakan & 101 & 45.3 \\
\hline & $\begin{array}{l}\text { membenahi diri menjadi lebih baik } \\
\text { - Karena bisa mendapatkan tiket } \\
\text { dengan harga yang lebih murah }\end{array}$ & 57 & 25.6 \\
\hline & $\begin{array}{l}\text { - Tidak ada pilihan lain karena } \\
\text { beberapa alasan }\end{array}$ & 25 & 11.2 \\
\hline
\end{tabular}


Dari tabel di atas, diketahui bahwa responden menggunakan AirAsiakarena harga yang murah dan banyak promosi yang diberikan oleh pihak maskapai AirAsia. Mereka mengganggap bahwa sudah terjamin keselamatannya walaupun, responden berharap agar ditingkatkan kembali tingkat keselamatannya. Responden menjawab bahwa terdapat masalah delay yang cukup lama dan mereka masih menggunakan maskapai penerbangan AirAsia karena mereka yakin akan membenahi diri menjadi lebih baik lagi.

\section{DISKUSI}

Hasil korelasi setiap tipe kepribadian terhadap kepercayaan merek diketahui bahwa tipe kepribadian neuroticism berpengaruh secara negatif dan signifikan, sedangkan tipe kepribadian lainnya berkorelasi positif dan signifikan yaitu agreeableness, conscientiousness, extraversion, dan openness to experience. Hasil korelasi positif berarti semakin tinggi skor pada tipe kepribadian maka brand trust maka semakin tinggi pula, dan sebaliknya. Sedangkan korelasi negatif pada tipe neuroticsm berarti semakin tinggi skor neurtoticsm maka brand trust semakin rendah.

Hasil dari penelitian ini mendukung hipotesis yaitu terdapat hubungan positif dan signifikan antara tipe kepribadian extraversion dengan brand trust. Seseorang yang memiliki ciri kepribadian extraversion adalah seseorang yang energik, optimis, dan cenderung mempercayai sesuatu yang dipilihnya (Pervin, Cervone, \& John, 2005). Hal ini sesuai dengan hasil penelitian yang dilakukan oleh Azam, Qiang, dan Sharif (2013) yang mengatakan bahwa individu extraversion cenderung lebih mudah percaya dan mereka lebih terlibat dalam aktivitas pada transaksi online dimana pada transaksi pembelian tiket maskapai AirAsiajuga harus melalui online. Dalam penelitian ini juga ditemukan bahwa individu dengan tipe kepribadian agreeableness sebesar 0.254 ( $p<0.01)$, berkorelasi positif yang berarti semakin tinggi skor tipe kepribadian agreeableness, maka brand trust terhadap merek juga semakin tinggi dan sebaliknya. Hal ini dikarenakan Individu yang memiliki tipe kepribadian agreeableness umumnya lebih cenderung mempercayai lingkungan sosial mereka dan memiliki kecenderungan untuk berusaha berhubungan baik dengan lingkungan sosial (Azam, Qiang, \& Sharif, 2013). Dengan kata lain, individu dengan tipe kepribadian agreeableness cenderung untuk menanggapi semua informasi yang diterima dari lingkungannya, sehingga konsumen dengan tipe kepribadian agreeableness cenderung lebih mudah mempercayai informasi yang diperolehnya dari berita-berita dan pendapat orang sekitarnya dalam hal brand trust pada jasa 
penerbangan AirAsia. Sehingga, ketika mendapatkan informasi yang positif maupun negatif mengenai Air Asia tipe kepribadian agreeableness akan lebih mudah percaya.

Kemudian, individu dengan tipe kepribadian conscientiousness berhubungan secara positif dan signifikan dengan brand trust, dimana individu dengan tipe kepribadian conscientiousness dicirikan sebagai individu yang teliti dan detail, mereka juga fokus pada perencanaan, serius dan cenderung berhati - hati dalam mengambil setiap keputusan (Pervin, Cervone, \& John, 2005).Citra yang diberikan AirAsiacukup kuat dengan didukung oleh pernyataan penumpang bahwa pihak AirAsiabertanggung jawab dan dapat diandalkan, menyebabkan individu dengan ciri yang detail dan berhati - hati dalam membuat keputusan percaya serta memilih menggunakan penerbangan AirAsia.

Trait kepribadian yang berkorelasi positif lainnya adalah openness dan extraversion. Seseorang dengan ciri kepribadian openness memiliki karakter yang kreatif, orisinil, memiliki pandangan yang luas serta lebih terbuka dan cenderung untuk mencoba hal baru (Pervin, 2005). Oleh karena itu, dalam hasil penelitian ini kaitan antara openness dengan brand trust adalah individu dengan ciri opennessyang lebih terbuka terhadap pengalaman cenderung akan lebih percaya dengan brand maskapai AirAsia.

Tipe kepribadian neuroticism berhubungan negatif dengan brand trust, dimana individu yang memiliki tipe kepribadian neuroticism dicirikan sebagai individu dengan emosi yang tidak stabil. Mereka sering mengalami kecemasan terhadap apapun dibandingkan dengan individu secara emosional yang stabil.Mereka juga sangat memiliki kekhawatiran terhadap suatu peristiwa yang negatif sehingga orang dengan tipe kepribadian tersebut cenderung tidak mempercayai kepercayaan suatu merek (Azam et al, 2013). Sehingga dari hasil penelitian, individu dengan tipe kepribadian neurotik cenderung khawatir pada resiko terkait daripada potensi kecelakaan udara saat menggunakan pesawat, sehingga individu neurotic cenderung sulit untuk mempercayai merek maskapai AirAsia.

Dari hasil deskriptif brand trust konsumen terhadap maskapai penerbangan AirAsiaditemukan cenderung rendah. Elliot dan Yannopulou (2007) menyebutkan bahwa kepercayaan konsumen terhadap suatu merek dan keputusan untuk membeli melibatkan persepsi terhadap resiko (perceived risk). Ketika level persepsi resiko dan harga dari produk yang akan dibeli tinggi, kepercayaan konsumen dipengaruhi oleh pengalaman-pengalaman sebelumnya dan seberapa reliabel produk atau jasa tersebut.Kepercayaan merupakan sebuah proses atau dinamika 
dan untuk produk dengan resiko dan level harga yang tinggi sebagaimana jasa penerbangan, agar dapat menjadi pilihan merek kepercayaan konsumen perluberfokus pada keterlibatan emosi dan keakraban konsumen terhadap merek. Dari data tambahan open ended questions dapat disimpulkan pula, konsumen memilih maskapai penerbangan AirAsiamayoritas karena selalu memberikan harga yang murah dan promosi yang menarik, konsumen percaya dengan keselamatan menggunakan maskapai AirAsiaakan tetapi konsumen berharap masih banyakpula perbaikan yang dilakukan agar menjadi lebih baik. Pengalaman-pengalaman sebelumnya dari konsumen juga mempengaruhi brand trust konsumen, akan tetapi dari jumlah frekuensi konsumen yang menggunakan jasa maskapai penerbangan Air Asia didapatkan mayoritas adalah 1-3 x per tahun sehingga keterlibatan emosional dan pengalaman sebelumnya yang rendah terhadap merek. Hasil penelitian ini juga menunjukkan kepercayaan konsumen terhadap maskapai AirAsia terus berubah karena dalam pemilihan untuk menggunakan jasa penerbangan AirAsia konsumen membandingkan dengan pilihan-pilihan dari jasa penerbangan lainnya.

\section{SIMPULAN DAN SARAN}

Menurut hasil penelitian ini, agreeableness, conscientiousness, extraversion, dan openness to experience memiliki korelasi positif dan signifikan dengan brand trust terhadap maskapai AirAsia. Temuan ini berbeda dengan pada domain neuroticism, dimana pada domain ini hubungannya bersifat negatif dengan brand trust.

Saran bagi penelitian selanjutnya, agar dapat menambahkan variabel terikat lainnya seperti loyalitas konsumen agar dapat diketahui apakah brand trust dapat berdampak pada loyalitas seseorang pada suatu merek. Saran praktis bagi pihak AirAsiaialah agar terus berusaha meningkatkan pelayanan serta keamanan pada maskapainya sehingga dapat menjadi sebuah brand yang terbaik, agar untuk menjaga hubungan baik dengan konsumen meskipun urusan bisnis sedang dalam proses ataupun telah usai. 


\section{REFERENSI}

Addani, S., \& Nofietasari. (2013). Analisa konsistensi perilaku pilihan pelanggan terhadap penawaran penjualan tiket antara penerbangan layanan penuh dan penerbangan biaya rendah. Ditemu kembali dari http://digilib.its.ac.id/ITS-paper-25021140004208/35065

Azam, A., Qiang, F., \& Sharif, S. (2013). Personality based psychological antecedents of consumers' trust in e-commerce. Journal of WEI Business and Economics, 2(1), pp. 31-40.

Delgado. E., Ballester. (2003). Development and validation of a brand trust scale. Journal of Market Research, 45(1), 35-54.

Edwina, I. P. (2012). Studi deskriptif the five-factor model of personality pada remaja usia 15 - 18 tahun. Ditemu kembali dari http://repository.maranatha.edu/1875/1/Studi\%20Deskriptif\%20The\%20FiveFactor\%20Model\%20of\%20Personality.pdf

Elliot, R., \& Yannopoulou, N. (2007). The nature of trusy in brands: A psychosocial model. European Journal Marketing, 41 (9), 988-998.

Feist, J., Feist, G. (2009). Theories of personality (7th ed.). New York, NY : McGraw Hills.

Ferrina. D. (2008). Merek dan psikologi konsumen: Implikasi pada strategi pemasaran. Yogyakarta : Graha Ilmu

Gravetter, F. J,. \& Forzano, L. B. (2012). Research methods for behavioral sciences $\left(\right.$ ed $\left.4^{\text {th }}\right)$. Belmont, CA: Wadsworth Cengage Learning.

Hidayat, S, N. (2010). Jumlah penumpang LCC naik 14\%. Ditemu kembali dari http://industri.kontan.co.id/news/jumlah-penumpang-lcc-naik-14-1

Iskandar, L. M., \& Zulkarnain. (2013). Penyesalan pasca pembelian ditinjau dari big five personality. Jurnal psikologi, 40(1), 81-91.

John, O. P., Donahue, E. M., \& Kentle, R. L. (1991). The Big Five Inventory - Versions $4 a$ and 54. California, CA: University of California.

Kementerian Perhubungan Republik Indonesia. (2015). Jumlah penumpang angkutan udara 2015 mencapai 72,6 juta orang. Ditemu kembali dari http://www.dephub.go.id/berita/baca/jumlahpenumpang-angkutan-udara-2014-mencapai-72,6-juta-orang/

Khoza. K., Harjati. L. (2012). Analisis brand trust dan brand loyalty konsumen Garuda Indonesia. Jurnal Ekonomi, 29 (324), 41 - 48.

Lestarini, A. H. (2015). Ingin semua orang nikmati penerbangan, AirAsia pun berdiri. Ditemu kembali dari http://ekonomi.metrotvnews.com/read/2015/01/02/339827/sejarah-berdirinyaairasia 
Mastuti. E. (2005). Analisis faktor alat ukur kepribadian big five (adaptasi dari IPIP) pada mahasiswa Suku Jawa. Jurnal INSAN,7(3), 264 - 276.

Peraturan menteri perhubungan no 77 tahun 2011. Tanggung jawab pengangkut angkutan udara. Ditemu kembali dari http://hubud.dephub.go.id/files/km/2011/PM\%2077.pdf

Pervin. L. A., Cervone. D., \& John. O. P. (2005). Personality: theory and research. Hoboken, NJ: John wiley \& Sons.

Prestasi AirAsia. (2015). Airasia Home Page. Ditemu kembali dari http://www.airasia.com/id/id/about-us/awards.page

Ramadhan, A, W. (2014). Bisnis LCC Meningkat Tajam di Indonesia. Ditemu kembali dari http://www.republika.co.id/berita/ekonomi/bisnis/14/02/20/n1akzk-bisnis-lcc-meningkattajam-di-indonesia

Ramdhani, N. (2012). Adaptasi bahasa dan budaya inventori Big five. Jurnal Psikologi, 39 (2), 189207.

Rizan. M., Saidani. B., Sari. Y. (2012). Pengaruh brand image dan brand trust terhadap brand loyalty teh botol sosro. Jurnal Riset Manajemen Sains Indonesia, 3(1), 1 - 17.

Saham AirAsia anjlok. (2014, 29 Desember). Antara News. Ditemu kembali dari http://www.antaranews.com/berita/471365/saham-airasia-anjlok-terburuk-sejak-2011.

Sugiyono. (2014). Metode penelitian pendidikan pendekatan kuantitatif, kualitatif dan $R \& D$. Bandung: Alfabeta.

Sukmana, Y. (2015, 27 Januari). AirAsia akui sedang hadapi masa paceklik. Ditemu kembali dari http://bisniskeuangan.kompas.com/read/2015/01/27/060800526/AirAsia.Akui.Sedang.Hadapi .Masa.Paceklik.

Supingah, I. (2015). Asal mula Low Cost Carrier. Ditemu kembali dari http://ekonomibisnis.suarasurabaya.net/news/2015/145803-Asal-Mula-Low-Cost-Carrier

Tarif murah aman terbang. (2015, 8 Januari). Berita Satu. Ditemu kembali dari http://sp.beritasatu.com/home/tarif-murah-aman-terbang/74458

Utomo, G. (2013). Hubungan antara kepercayaan pada pedagang internet dan kepribadian big five dengan intensi membeli pakaian melalui internet. Ditemu kembali dari http://download.portalgaruda.org/article.php?article=123284\&val=5545\&title=Hubungan $\% 20$ Antara\%20Kepercayaan\%20Pada\%20Pedagang\%20Internet\%20Dan\%20Kepribadian\%20Big \%20Five\%20Dengan\%20Intensi\%20Membeli\%20Pakaian\%20Melalui\%20Internet.

Wardana, D. (2011). Pengaruh kepribadian konsumen pada pilihan merek sebagai konsep diri pada kategori produk. Jurnal Aset, 13(1), 21-35. 
Yulianingsih, T. (2015). 1-1-2007: Saat Adam Air menghilang tanpa jejak. Ditemu kembali dari http://news.liputan6.com/read/2154868/1-1-2007-saat-adamair-menghilang-tanpa-jejak. 